GUIMARÃES, R. e CARVALHO, G.D. Pteridium aquilinum: Importância para saúde pública. PUBVET, Londrina, V. 8, N. 9, Ed. 258, Art. 1707, Maio, 2014.

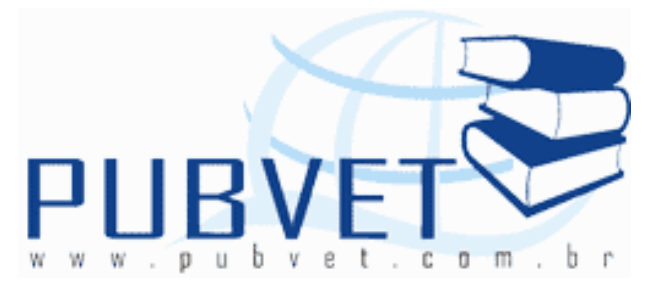

PUBVET, Publicações em Medicina Veterinária e Zootecnia.

\title{
Pteridium aquilinum: Importância para saúde pública
}

\author{
Raniela Guimarães ${ }^{1}$, Gabriel Domingos Carvalho ${ }^{2}$
}

1.Médica Veterinária. Pós-Graduanda em Produção e Reprodução de Bovinos Faculdade de Ciências Biológicas e da Saúde (FACISA/UNIVIÇOSA), Viçosa, MG, Brasil.

2.Professor Doutor - Instituto Federal Norte de Minas Gerais (IFNMG Campus Salinas), Salinas, MG, Brasil. E-mail: gabriel.carvalho@ifnmg.edu.br

\section{Resumo}

Desde a Antiguidade já se conhece as potencialidades tóxicas das plantas, as quais são capazes de causar danos à saúde do homem e dos animais. No Brasil é muito frequente a ocorrência de casos de intoxicação em bovinos causados por ingestão de plantas tóxicas. O desconhecimento das espécies vegetais tóxicas é apontado como o principal fator para ocorrência desses acidentes, desse modo, a melhor forma de prevenir é através do conhecimento e da divulgação a respeito do assunto. Neste contexto, este trabalho apresenta a importância dos quadros de intoxicação de animais e humanos por Pteridium aquilinum, comumente conhecida como "samambaia-do-campo". Este trabalho apresenta uma revisão bibliográfica que enfoca na importância da $P$. aquilinum para saúde pública.

Palavras-chave: bovinos, leite, samambaia. 
GUIMARÃES, R. e CARVALHO, G.D. Pteridium aquilinum: Importância para saúde pública. PUBVET, Londrina, V. 8, N. 9, Ed. 258, Art. 1707, Maio, 2014.

\title{
Pteridium aquilinum: Importance for public health
}

\begin{abstract}
From antiquity already know the potential toxic plants, which are capable of causing damage to human health and animals. In Brazil it is very frequent occurrence of cases of poisoning in cattle caused by eating poisonous plants. Ignorance of the toxic species is identified as the main factor for the occurrence of these accidents, so the best way to prevent it is through the knowledge and dissemination of the subject. In this context, this paper presents the importance of the intoxication of animals and humans by Pteridium aquilinum, commonly known as "fern-de-camp." This paper presents a literature review that focuses on the importance of $P$. aquilinum to public health.
\end{abstract}

Keywords: cattle, milk, fern.

\section{INTRODUÇÃO}

Pteridium aquilinum, conhecida popularmente como "samambaia-docampo" ou simplesmente "samambaia" (TOKARNIA et al., 2000; GORNIAK, 2008; SILVA, 2010), está presente na maioria das propriedades rurais de criação extensiva e semi-extensiva do mundo (ULIAN, 2010), e é considerada a única planta naturalmente carcinogênica para os animais (SHAHIN et al., 1999; YAMADA, et al., 2007).

É uma das plantas tóxicas mais importantes no mundo, não só pela sua distribuição cosmopolita e intoxicação de rebanhos em diversas partes do mundo, mas também pelo seu alto potencial carcinogênico observado em animais e seres humanos que se alimentam desta planta (ALONSO-AMELOT, 1999; ALONSO-AMELOT \& AVERDANO, 2002).

O principio tóxico relacionado à carcinogênese é o ptaquilosídeo, um glicosídeo norsesquiterpeno, considerado o principal entre os encontrados nesta planta (FRANÇA, 2002; MENDEZ \& RIET-CORREA, 2006). 
GUIMARÃES, R. e CARVALHO, G.D. Pteridium aquilinum: Importância para saúde pública. PUBVET, Londrina, V. 8, N. 9, Ed. 258, Art. 1707, Maio, 2014.

O interesse pela toxicidade produzida pela $P$. aquilinum não se limita somente à criação animal; neste sentido, estudos epidemiológicos realizados no Brasil associam o consumo de brotos e rizomas de $P$. aquilinum com uma maior incidência de câncer de esôfago e estômago em humanos (MARLIÉRE et al., 1998; SANTOS, 1999).

Além da ingestão direta dos princípios tóxicos da $P$. aquilinum pela alimentação, os humanos podem ingeri-los de forma indireta, pois os animais que consomem a planta excretam o ptaquilosídeo no leite (HOEHNE, 1939; ALONSO- AMELOT et al., 1993; ALONSO-AMELOT et al., 1996). Os riscos à população humana não se restringem apenas ao consumo direto da planta e a ingestão de leite e derivados, mas também através da ingestão de carne de animais intoxicados por plantas (CARVALHO, 2005).

Shahin et al. (1999) demonstraram que o leite de vacas que consomem samambaia contém quantidades significativas de ptaquilosídeo e isto representa um risco para saúde pública, em virtude de suas propriedades cancerígenas.

Experimentalmente já se observou que animais que ingeriram leite de vacas que consumiam $P$. aquilinum apresentaram alterações deletérias na atividade da medula óssea (EVANS et al., 1987) e indução de processos neoplásicos (EVANS et al., 1972; PAMUKCU et al., 1980).

Neste sentido, a $P$. aquilinum torna-se uma planta de interesse tanto em medicina veterinária quanto humana, devido as suas propriedades carcinogênicas.

\section{Pteridium aquilinum}

P. aquilinum (L.) Kuhn, pertence ao filo Pteridophyta e à família Dennstaedtiaceae (anteriormente conhecida como Polypodiaceae). De acordo com recentes classificações taxonômicas possui nove subespécies com distribuição mundial (VETTER, 2009). Existem duas subespécies de maior importância: $P$. aquilinum aquilinum e $P$. aquilinum caudatum e doze variedades. A subespécie $P$. aquilinum aquilinum é prevalente no hemisfério 
GUIMARÃES, R. e CARVALHO, G.D. Pteridium aquilinum: Importância para saúde pública. PUBVET, Londrina, V. 8, N. 9, Ed. 258, Art. 1707, Maio, 2014.

Norte e África, e comporta oito variedades e a subespécie $P$. aquilinum caudatum é prevalente no hemisfério Sul e comporta quatro variedades (SHAHIN, 1999).

A $P$. aquilinum é uma planta cosmopolita, cuja presença é observada em todos os continentes. (TOKARNIA et al., 2000; GORNIAK, 2008), exceto na Antártica (ALONSO-AMELOT, 1997; HOJO-SOUZA et al., 2010; VILLALOBOS, 2011). No Brasil ocorre principalmente em regiões montanhosas, desde o sul da Bahia até o Rio Grande do Sul, sendo que em alguns estados (Acre, Amazonas, Mato Grosso e Pernambuco) também é considerada como planta invasora de pastos. $P$ aquilinum desenvolve-se melhor em regiões frias e de boa pluviosidade, com solos ácidos e bem drenados, como encostas de morro, porém adapta-se também a outros ambientes (TOKARNIA et al., 2000).

É uma planta rasteira, rizomatosa, com folhas grandes (60 a $180 \mathrm{~cm}$ de comprimento por 60 a $120 \mathrm{~cm}$ de largura), bipinadas, com pinas profundamente lobadas, face superior lisa e verde escura, com pelos lanunginosos na face inferior. Geralmente forma touceiras densas (MELO, 2006). A ampla disseminação da $P$. aquilinum deve-se a características tais como: resistência de seus rizomas ao frio (inverno) e ao calor (queimadas); resistência da planta ao ataque de insetos e de microorganismos; capacidade de resistir a climas desfavoráveis, sequestrar nutrientes do solo a longas distâncias (com consequente exclusão de espécies competitivas), além de se reproduzir por meio de um grande número de esporos carreados pelo vento (ALONSO-AMELOT \& AVERDANO, 2002).

Uma característica da $P$. aquilinum é manifestar exuberância no seu crescimento em ambientes onde há pouca competição (GORNIAK, 2008). Também é a primeira planta a crescer em áreas recém queimadas ( $M I T I C H$, 1999). O desmatamento e a transformação de extensas áreas para uso agropecuário ou agrícola têm contribuído na disseminação da $P$. aquilinum que rapidamente coloniza estes espaços, dessa forma tornou-se mais frequente as intoxicações de bovinos e ovinos que se alimentam de suas folhas, assim como o contato humano com a planta (HOJO-SOUZA et al., 2010). 
GUIMARÃES, R. e CARVALHO, G.D. Pteridium aquilinum: Importância para saúde pública. PUBVET, Londrina, V. 8, N. 9, Ed. 258, Art. 1707, Maio, 2014.

P. aquilinum é tóxica verde ou seca e tem poder cumulativo (MELO, 2006). O principal agente cancerígeno e principio tóxico conhecido é o ptaquilosídeo, um glicosídeo norsesquiterpeno (FRANÇA, 2002; MENDEZ \& RIET-CORREA, 2006), que apresenta concentrações variáveis podendo atingir $12.945 \mu \mathrm{g} / \mathrm{g}$ de planta seca, porém esta característica depende do genótipo de Pteridium (SMITH et al., 1994; YAMANDA et al., 2007; ROPERTO et al., 2010).

A concentração dos diversos componentes tóxicos da $P$. aquilinum varia consideravelmente em função do estágio de crescimento e da época do ano, sendo mais tóxicas as plantas mais jovens. As porções do caule que ficam enterradas (rizomas) e as folhas novas enroladas (báculo ou munheca) contêm o princípio tóxico em concentração aproximadamente cinco vezes mais do que a encontrada nas folhas maduras (RADOSTIST et al., 2002).

Ainda, o tipo de solo, o clima e a geografia interferem na toxicidade, tanto entre variedades, como em exemplares da mesma variedade (ALONSOAMELOT, 1999). Esse fato foi demonstrado por Cruz et al., (2005) onde a altitude, aliados a época de colheita da $P$. aquilinum contribuíram para baixas concentrações de ptaquilosídeo e, consequentemente, menor ocorrência de neoplasias nos ratos tratados experimentalmente.

O ptaquilosídeo é estável à temperatura ambiente por mais de uma semana e a baixas temperaturas (entre $-20^{\circ} \mathrm{C}$ e $0^{\circ} \mathrm{C}$ ) por mais de seis meses. A meia vida varia de 1,2 minutos a 2,9 horas dependendo das condições em que se encontra (YAMADA et al., 2007). Porém, é um composto instável em solução aquosa na presença de ácido, base ou calor, degradando-se muito rapidamente em pterosina $\mathrm{B}$ e $\mathrm{D}-(+)$. Uma característica importante é que, em condições alcalinas, o ptaquilosídeo pode dar origem a um conjugado denominado dienona. A dienona é capaz de associar-se quimicamente a uma infinidade de proteínas com terminais amino expostos, como o DNA, já que o ptaquilosídeo atravessa a membrana celular e nuclear das células. No núcleo causa uma alteração permanente e irreparável em determinados genes. Esses genes são os que codificam a ativação de outros genes ou tem a função reguladora de outros processos bioquímicos. Desse modo, a dienona propicia a 
GUIMARÃES, R. e CARVALHO, G.D. Pteridium aquilinum: Importância para saúde pública. PUBVET, Londrina, V. 8, N. 9, Ed. 258, Art. 1707, Maio, 2014.

formação e multiplicação de um tecido afuncional e canceroso (GORNIAK, 2008).

\section{INTOXICAÇÃO EM BOVINOS POR Pteridium aquilinum}

No Brasil é muito frequente a ocorrência de casos de intoxicação em bovinos causados por ingestão de plantas tóxicas. O desconhecimento das espécies vegetais tóxicas é apontado como o principal fator para ocorrência desses acidentes, desse modo, a melhor forma de prevenir é através do conhecimento e da divulgação a respeito do assunto (CARVALHO, 2009).

A maioria das plantas tóxicas é consumida pelos animais em razão da escassez de alimentos e da mudança de animais famintos para pastagens que possuem tais plantas (CARVALHO, 2005), porém, no caso da $P$. aquilinum, por ser uma planta palatável, os episódios de consumo por parte dos animais é bem mais frequente (CARVALHO, 2009). Há indícios de que os animais possam desenvolver vício, caracterizando, com isso, ingestões repetidas e compulsivas. Por fim, intoxicam pelo fornecimento de feno contaminado pela $P$. aquilinum (TOKARNIA et al., 2000; MELO, 2006).

Dependendo da quantidade e do tempo de ingestão, os bovinos apresentam três formas clínicas distintas atribuídas à ação radiomimética da intoxicação com $P$. aquilinum: diátese hemorrágica, hematúria enzoótica bovina e carcinoma das vias digestivas superiores (CARVALHO, 2009).

A Síndrome Hemorrágica Aguda (diátese hemorrágica). As alterações aparecem quando os animais ingerem quantidades diárias maiores que $10 \mathrm{~g} / \mathrm{Kg}$ da planta durante algumas semanas a poucos meses (TOKARNIA et al., 2000). A doença caracteriza-se por febre, anorexia, parada ruminal, fezes com sangue, diarréia fétida, respiração ofegante, hemorragias cutâneas nas mucosas das narinas, vulva, reto e conjuntiva, além de úlceras na boca. 0 hemograma revela anemia acentuada, leucopenia e trombocitopenia (TOKARNIA et al., 2000; PINTO et al., 2007; GORNIAK, 2008).

A Hematúria Enzoótica Bovina ocorre quando há ingestão da planta em quantidades inferior a $10 \mathrm{~g} / \mathrm{Kg} /$ dia durante um ou mais anos (TOKARNIA et al., 
GUIMARÃES, R. e CARVALHO, G.D. Pteridium aquilinum: Importância para saúde pública. PUBVET, Londrina, V. 8, N. 9, Ed. 258, Art. 1707, Maio, 2014.

2000).A doença caracteriza-se principalmente por hematúria intermitente, anemia e emagrecimento (TOKARNIA et al., 2000; GORNIAK, 2008). A hematúria enzoótica bovina é determinada por processos neoplásicos ou hiperplásicos da mucosa da bexiga (DURÃO, 1995). Esse quadro pode persistir por longo tempo (até mais de um ano), seguindo-se o óbito por caquexia (MENDEZ \& RIET-CORREA, 2006). Geralmente os animais que manifestam essa forma da doença têm mais de dois anos vida (TOKARNIA et al., 2000).

Ainda, a ingestão crônica de Pteridium aquilinum, em bovinos, pode promover o desenvolvimento de carcinomas das vias digestivas superiores, principalmente: língua, faringe, esôfago e rúmen. Animais com mais de seis anos vida são os mais acometidos após ingestão por tempo prolongado de pequenas quantidades. A doença caracteriza-se por formações tumorais no trato digestivo, com nódulos de diferentes tamanhos, os quais causam obstrução mecânica. A manifestação clinica são: tosse, regurgitamento, timpanismo, diarréia, emagrecimento (SOUZA \& GRAÇA, 1993; TOKARNIA et al.; 2000; GORNIAK, 2008).

Destas três formas clínicas, classificamente conhecidas, a incidência maior de casos refere-se à Hematúria Enzoótica dos bovinos e a menor aos casos de Carcinoma Epidermóides do trato digestivo superior, talvez pelo fato de menor expectativa de vida dos bovinos. Os casos agudos, embora ocorram com menor incidência, sempre representam muitos óbitos (MARÇAL, 2002; MARÇAL, 2003).

Não é recomendada a ingestão de carne de animais que vieram a óbito por intoxicação por plantas. Os animais em lactação e que cursam um quadro de intoxicação devem ser afastados da produção leiteira até que o seu quadro clínico volte ao normal (CARVALHO, 2005).

\section{IMPORTÂNCIA PARA SAÚDE PÚBLICA}

De acordo com Alonso-Amelot et al. (1996) as vacas expostas esporadicamente a $P$. aquilinum apresentarão o ptaquilosídeo no leite algumas 
GUIMARÃES, R. e CARVALHO, G.D. Pteridium aquilinum: Importância para saúde pública. PUBVET, Londrina, V. 8, N. 9, Ed. 258, Art. 1707, Maio, 2014.

horas após a ingestão do glicosídeo, que continua a ser excretado no leite por um período de $80 \mathrm{~h}$ após a última ingestão.

Já foi comprovado experimentalmente a indução de neoplasias de bexiga e intestino em ratos através do fornecimento de leite produzido por vacas alimentadas com P. aquilinum (PAMUKCU et al., 1980). Evans et al. (1972) demonstraram que $o$ leite proveniente de vacas que se alimentam regularmente de brotos de $P$. aquilinum, contém ptaquilosídeo e causa câncer em roedores. Um experimento envolvendo ratos alimentados com $30 \mathrm{~g} / \mathrm{Kg} / \mathrm{dia}$ relatou não apenas o aumento no índice de neoplasias, mas também a alteração na morfologia de vários órgãos como baço, timo, linfonodos mesentéricos e placas de Peyer. Isso demonstra que os princípios ativos presentes no $P$. aquilinum além de serem cancerígenos também alteram o sistema imunológico dos animais e provavelmente, dos humanos que venham a ingerir de alguma forma essas toxinas (LATORRE, 2006). Experimentalmente, observou-se também que bezerros que receberam leite de vacas que consumiam dietas suplementadas com $P$. aquilinum por período prolongado, apresentaram alterações deletérias na atividade da medula óssea (EVANS et al., 1987).

O ptaquilosídeo é excretado no leite numa concentração de cerca de 8,6 $\pm 1,2 \%$ da quantidade ingerida pela vaca, e é linearmente dose dependente, sendo que começa 38 horas após a alimentação das vacas com $P$. aquilinum, onde em uma ingestão constante a quantidade excretada diariamente aumenta progressivamente até o quarto dia quando atingem um platô. Depois de cinco dias continua a ser excretado em aproximadamente a mesma taxa de 62 horas após último tratamento. Então, diminui rapidamente e desaparece completamente do leite 86 horas após a última ingestão (ALONSO-AMELOT et al., 1996; ALONSO-AMELOT et al., 1998).

Se alguma pessoa bebe dois copos de leite $(500 \mathrm{~mL})$ de uma vaca que esteja consumindo $7 \mathrm{~kg}$ de $P$. aquilinum, que contém aproximadamente $5 \mathrm{~g}$ de ptaquilosídeo, e que tem uma produção de 20 litros/dia, essa pessoa estará ingerindo entre 2 e $10 \mathrm{mg}$ deste potente carcinógeno. Quando o principio ativo 
GUIMARÃES, R. e CARVALHO, G.D. Pteridium aquilinum: Importância para saúde pública. PUBVET, Londrina, V. 8, N. 9, Ed. 258, Art. 1707, Maio, 2014.

é ingerido pelo homem, parte dele é degradado pelo ácido clorídrico do suco gástrico, mas parte é absorvida pelo trato digestório, sendo essa última parte a consequente propensão ao desenvolvimento de câncer, em longo prazo (ALONSO-AMELOT, 1999).

Conforme Rasmussen (2003) no processo de pasteurização do leite ocorre uma diminuição de 50 a $75 \%$ na presença do ptaquilosídeo, mas isso não o torna menos perigoso ao organismo humano, já que há um acúmulo do principio tóxico no organismo.

Outro meio de ingestão indireta de $P$. aquilinum pelo homem é o consumo de carne contaminada, mas necessita-se de mais estudos para esta confirmação (CARVALHO, 2005). Os riscos apontados à população humana não se restringe apenas à ingestão de produtos provenientes de animais que ingeriram $P$. aquilinum, mas também por meio do contato direto como: ingestão da planta, contato físico (inalação dos esporos ou ingestão de água contaminada) (POTTER \& BAIRD, 2000; CRUZ \& BRACARENSE, 2004).

$P$. aquilinum é consumida, em quantidades significativas, em algumas partes do mundo, notadamente no Japão, partes dos Estados Unidos, no Canadá, na China, na Sibéria (FENWICK, 1988), e até mesmo no Brasil, principalmente em Minas Gerais (SANTOS et al., 1986; SANTOS et al., 1987; MARLIÉRE et al., 1998). Para o consumo o broto de $P$. aquilinum é fervido na água com cinzas ou bicarbonato de sódio, a água de fervura é descartada e o produto é ingerido como salada. Este procedimento reduz, porém não elimina a carcinogenicidade (SANTOS et al., 1986; SUGIMURA, 2000). Santos et al. (1992) avaliando a água de fervura do broto de $P$. aquilinum concluíram que esta também é altamente carcinogênica em ratos.

Estudos epidemiológicos na população humana têm demonstrado uma estreita associação entre consumo de $P$. aquilinum e câncer. Níveis significativamente elevados de anormalidades cromossômicas, como quebras de cromátides, têm sido demonstrados em linfócitos do sangue de pessoas que consomem brotos ou folhas jovens da $P$. aquilinum (RECOUSO et al., 2003). 
GUIMARÃES, R. e CARVALHO, G.D. Pteridium aquilinum: Importância para saúde pública. PUBVET, Londrina, V. 8, N. 9, Ed. 258, Art. 1707, Maio, 2014.

As pessoas que tem o hábito de consumir o broto de $P$. aquilinum apresentam 5,47 \% mais chances em desenvolverem câncer de esôfago e estômago do que os que não consomem (MARLIÉRE et al., 1998). Um estudo realizado na Costa Rica relatou um aumento de duas a três vezes na presença de carcinoma gástrico em crianças alimentadas com leite bovino de região endêmica de $P$. aquilinum (VILLALOBOS-SALAZAR, 1985).

Considera-se ainda, a contaminação do solo e das águas pelo processo de lixiviação, e que a ingestão do princípio tóxico também possa ocorrer por meio do consumo de água armazenada em reservatórios localizados em áreas muito invadidas por P. aquilinum (FENWICK, 1988; RASMUSSEN, 2003; YAMADA et al., 2007).

\section{CONSIDERAÇÕES FINAIS}

Devido à grande extensão territorial e condições climáticas favoráveis do Brasil, o sistema de produção de bovinos predominante no país é do tipo extensivo, fato que predispõem o contato dos animais com $P$. aquilinum, que é uma planta cosmopolita.

O risco à saúde humana provocado por $P$. aquilinum é evidente, devido as suas propriedades cancerígenas. Isto ocorre por meio da ingestão direta da planta ou indireta, através de produtos de origem animal, porém este risco é pouco conhecido pela população.

O leite, considerado um alimento saudável, altamente nutritivo e isento de substâncias nocivas à saúde, em função de seu alto consumo, é a principal forma de intoxicação por $P$. aquilinum em humanos.

Ainda não existe nenhum método disponível pela Rede Brasileira de Laboratórios de Controle de Qualidade do Leite (Redeleite) capaz de identificar os resíduos de plantas tóxicas nos produtos de origem animal. Assim sendo, os animais em lactação que apresentam quadro clínico de intoxicação por planta devem ser afastados da ordenha. Ressalta-se, também, a importância do profissional Médico Veterinário nesses diagnósticos e recomendações, evidenciando a sua contribuição na saúde humana. 
GUIMARÃES, R. e CARVALHO, G.D. Pteridium aquilinum: Importância para saúde pública. PUBVET, Londrina, V. 8, N. 9, Ed. 258, Art. 1707, Maio, 2014.

Além disso, de acordo com Riet-Correa e Medeiros (2001) são desconhecidos os princípios ativos de, pelo menos, 32 das 88 espécies tóxicas descritas no Brasil. Sendo assim, pode existir uma grande possibilidade de que outras plantas tóxicas, com mesmo princípio ativo da $P$. aquilinum, ou similar, que ainda não foi descoberto, possa trazer danos à saúde dos animais e das pessoas.

\section{REFERÊNCIAS BIBLIOGRÁFICAS}

ALONSO-AMELOT, M.E.; CASTILLO, U.; DE JONGH, F. Passage of the bracken fern carcinogen ptaquiloside into bovine milk. Le Lait, v.73, p.323-332, 1993.

ALONSO-AMELOT, M.E.; CASTILLO, U.; SMITH, B.L.; LAUREN, D.R. Bracken ptaquiloside in milk. Nature, v.382, n.6592, p. 587, 1996.

ALONSO-AMELOT, M.E. The link between bracken fern and stomach cancer: milk. Nutrition, V.13, nos.78, 1997.

ALONSO-AMELOT, M.E.; CASTILLO, U.; SMITH, B.L.; LAUREN, D.R. Excretion, through milk, of ptaquiloside in bracken-fed cows. A quantitative assessment. Le Lait, v.78, p.413-423, 1998.

ALONSO-AMELOT, M.E .Helecho macho, salud animal y salud humana. Revista de la Facultad de Agronomia (Luz). 1999. 16: 528-547.

ALONSO- AMELOT, M.E.; AVENDANO, M. Human carcinogenesis and bracken fern: a review of the evidence. Current Medicinal Chemistry, v.9, p.675-686, 2002.

CARVALHO, G.D. Principais plantas tóxicas causadoras de morte súbita em bovinos na região Sul do Estado do Espírito Santo. Monografia (Graduação). Universidade Federal do Espírito Santo - Centro de Ciências Agrárias. Alegre-ES, 2005. 64p.

CARVALHO, G.D. Quadro clínico-patológico das intoxicações por Samambaia (Pteridium aquilinum) em bovinos. PUBVET, Londrina, V. 3, N. 4, Art\#499, Fev 1, 2009.

CRUZ, G.D.; BRACARENSE, A.P.F.R.L. Toxicidade da samambaia (Pteridium aquilinum (L.)Kuhn para saúde animal e humana. Semina: Ciências Agrárias, Londrina, v.25, n.3, p.249-258, 2004.

CRUZ, G.D.; BRACARENSE, A.P.F.R.L; YAMASAKI, L.; CORTEZ, D.E.A. Alterações anátomohistopatológicas em ratos submetidos à dieta com extrato de broto de samambaia (Pteridium aquilinum var. arachnoideum) de dois municípios do estado do Paraná. Arquivo Brasileiro de Medicina Veterinária e Zootecnia. v.57,n.3, Belo Horizonte, Jun, 2005.

DURÃO, J.F.C.; FERREIRA, M.L.; CABRAL, A.; PELETEIRO, M.C.; AFONSO, F.; CORREIA, J. Aspectos anatomopatológicos e clínicos da hematúria enzoótica dos bovinos. Revista Portuguesa de Ciências Veterinárias, Lisboa, v.xc, n.515, p. 132-137, 1995.

EVANS, I.A.; JONES, R.S.; MAINWARING - BURTON, R. Passage of bracken fern toxicity into milk. Nature, v. 237, p.107-108, 1972.

EVANS, I.A. Bracken carcinogenicity. In: James G.V. (ed.). Reviews on Environmental Health. Int. Quart. Scient. Reviews v.7, p. 161-199, 1987.

FENWICK, G.R. Bracken (Pteridium aquilinum) Toxic Effects and Toxic Constituents. Journal of the science of food and agriculture. V.46, n.2, p.147-173,1988. 
FRANÇA, T.N; TOKARNIA, C.H; PEIXOTO, P.V. Enfermidades determinadas pelo principio radiomimético de Pteridium aquilinum (Polypodiaceae). Pesquisa Veterinária Brasileira, v.22, n.3, Rio de Janeiro, 2002.

GORNIAK, S.L. Plantas tóxicas de interesse agropecuário. In: SPINOSA, H.S., GORNIAK, S.L.; NETO, J.P. ed. Toxicologia aplicada à Medicina Veterinária. 1 ed. Manole: São Paulo,p.428-432, 2008.

HOEHNE, F.C. Plantas e substâncias vegetais tóxicas e medicinais. São Paulo: Graphicars. 1939, 355 p.

HOJO-SOUZA, N.S.; CARNEIRO, C.M.; SANTOS, R.C. Pteridium aquilinum: O que sabemos e o que ainda falta saber. Biosci.j., Uberlândia, v.26, n.5, p. 798-808, 2010.

LATORRE, A.O. Avaliação dos efeitos imunotóxicos da Pteridium aquilinum. Estudo em camundongos. Dissertação de Mestrado, Universidade de São Paulo, São Paulo,2006.

MARÇAL, W.S. Aspecto clínico epidemiológicos da toxidez da samambaia em bovinos. Ciência Veterinária nos Trópicos, Recife - PE, v.5, n.2 e 3, p. 61-69, 2002.

MARÇAL, W.S. A intoxicação por samambaia em bovinos criados no Estado do Paraná. Semina: Ciências Agrárias, Londrina, v.24, n.1, p.197-208, 2003.

MARLIÉRE, C. A.; SANTOS, R.C.; GALVÃO, M. A. M.; SOARES, J.F.; EVANGELISTA, C.L.M.; GOMES, R.Q.F. Ingestão de broto de samambaia e risco de câncer de esôfago e estômago na região de Ouro Preto, MG. Revista Brasileira Cancerologia, v.44, p.225-229, 1998.

MENDEZ, M. D. C.; RIET - CORREA, F. Intoxicação por plantas e micotoxinas. In: RIETCORREA, F; SCHILD, A.L; MENDEZ, M.D.C; LEMOS, R.A.A. ed. Doenças de Ruminantes e Equinos, 2 ed, Varela: São Paulo, v.2, p.265-267, 2006.

MELO M. M. Plantas que causam aplasia de medula óssea e formação de neoplasias. Cadernos Técnicos Veterinária e Zootecnia, v.49, p.47-51, 2006.

MITICH, L.W. Brackenfern, Pteridium aquilinum (L.) Kuhn. Weed Technology, v.13, p.429432, 1999.

PAMUKCU, A.M., WANG, C.Y., HATCHER, J., BRYAN, G.T. Carcinogenicity of tannin and tanninfree extracts of bracken fern (Pteridium aquilinum) in rats. Journal of National Cancer Institute v.65, p.131-136, 1982.

PINTO, C; PELETEIRO, M.C; LOBO, M.A; MACHADO, J; SILVA, L. Intoxicação aguda pelo feto comum (Pteridium aquilinum (L.) kuhn). Revista Portuguesa de Ciências Veterinárias, 102(563-564), p.289-298, 2007.

POTTER, D.M; BAIRD, M.S. Carcinogenic effects of ptaquiloside in bracken fern and related compounds. British Journal of Cancer, v.83 (7), p.914-920, 2000).

RADOSTITS, O.M; GAY, C.C; BLOOD, D.C; HINCHCLIFF, K.W. ed. Clínica Veterinária Um tratado de Doenças dos bovinos, Ovinos, Suínos, Caprinos e Equinos. 9ed. Guanabara, Rio Janeiro, p.1498 -1501, 2002.

RASMUSSEN, L.H. 2003. Ptaquiloside - na environmental hazard? Occurrence and fate of a Bracken (Pteridium sp.) toxin in terrestrial environments. Thesis conducted under the Ph.D, The Royal Veterinary and Agricultural University, Denmark.

RECOUSO, R.C, STROCCO DOS SANTOS, R.C.; FREITAS, R.; SANTOS, R.C.; FREITAS, A.C.; BRUNNER,O.; BEÇAL, W.; LINDSEY, C.J. Clastogenic effect of bracken fern (Pteridium aquilinum $\mathrm{V}$. arachnoideum) diet in peripheral lymphocytes of human consumers: preliminary data. Veterinary and Comparative Oncology, v.1, p.22-29, 2003. 
RIET-CORREA, F.; MENDEZ, R.M. Intoxicações por plantas em ruminantes no Brasil e no Uruguai: importância econômica, controle e riscos para a saúde pública. Pesquisa Veterinária Brasileira, v.21, n.1, Rio de Janeiro, 2001.

ROPERTO, S.; BORZACCHIELLO, G.; BRUN,R.; LEONARDI, L.; MAIOLINO,P.; MARTANO,M.; PACIELLO, O.; PAPPARELLA, S.; RESTUCCI,B.; RUSSO,V.; SALVATORE,G.; URRARO,C.; ROPERTO,F. A review of bovine urothelial tumours and tumour-like lesions of the urinary bladder. J Comp. Pathol, v.142, p.95-108, 2010.

SANTOS, R.C.; HOJO, E.S.; BRASILEIRO-FILHO, G. Studies on the possible carcinogenicity of bracken fern (Pteridium aquilinum) fron Ouro Preto, MG, Brasil. Ciência e Tecnologia de Alimentos, v.6, n.1, p.93-98, 1986.

SANTOS, R.C; BRASILEIRO-FILHO, G; HOJO, E.S. Induction of tumors in rats by bracken fern (Pteridium aquilinum) from Ouro Preto (Minas Gerais). Braz. J.Med.Biol. Res, v. 20, p.73-77, 1987.

SANTOS, R.C.; BRASILEIRO-FILHO. ; SILVA, M.E. Tumorigeniciy of boiling water extract of bracken fern (Pteridium aquilinum (L.) kuhn). Ciência e Tecnologia de Alimentos, v.12, n.1, p.72-76, 1992.

SANTOS, R.C. Avanços na pesquisa com broto de samambaia usado como alimento em Minas Gerais. Revista da Pesquisa \& Pós Graduação, v.1, n.1, 1999.

SHAHIN, M.; SMITH, B.L.; PRAKASH, A.S. Bracken carcinogenis in the human diet. Mutation Research. 443:69-79, 1999.

SILVA, S. Plantas tóxicas inimigo indigesto. Aprenda Fácil, Viçosa, MG, p.99-101, 2010.

SMITH, B.L; SEAWRIGHT, A.A; NG, J.C; HERTLE, A.T; THOMSON, J.A; BOSTOCK, P.D. Concentration of ptaquiloside, a major carcinogen in bracken fern (Pteridium ssp.), from eastern Australia and from a cultivated worldwide collection held in Sydney, Australia. Natural Toxins, 2, 347-353, 1994.

SOUZA, M.V.; GRAÇA, D.L. Intoxicação crônica por Pteridium aquilinum em bovinos. Ciência Rural, Santa Maria, v.23, n.2, p.203-207, 1993.

SUGIMURA, T. Nutrition and dietary carcinogens. Carcinogenesis, v.21, n.3, p. 387-395, 2000.

TOKARNIA, C.H.; DOBEREINER, J.; PEIXOTO, P.V. Plantas tóxicas do Brasil. Rio de Janeiro: Helianthus, 2000, 178-185.

ULIAN, C.M.V.; BAPTISTA, A.A.S.; VENTURA, R.F.A.; SAKATE, M. Pteridium aquilinum na alimentação humana: Uma Revisão. Acta Veterinária Brasílica, v.4, n.2, p.64-69, 2010.

VETTER, J. A biological hazard of our age: Bracken fern [Pteridium aquilinum (L.) Kuhn] - A review. Acta Veterinária Hungarica, v.57, n.1, p.183-186.

VILLALOBOS, J. Últimos descubrimientos sobre el efecto carcinogénico del helecho macho que comen nuestras vacas. Capturado em 10 set. 2011. Online. Disponível na Internet http://www.una.ac.cr/ambi/revista/82/villalobos.htm

VILLALOBOS-SALAZAR, J. Carcinogenicidad del Pteridium aquilinum y alta incidencia del cancer gástrico em Costa Rica. Rev. Cost. Cienc. Med, v.6, p.131-139, 1985.

YAMADA, K; OJIKA, M; KIGOSHI, H. Ptaquiloside, the major toxin of bracken, and related terpene glycosides: chemistry, biology and ecology. Natural Product Reports, 24, p.798813, 2007. 